\title{
CONTRIBUIÇÕES DO PIBID QUÍMICA DA UFFS: UMA REFLEXÃO ACERCA DO (DES)INTERESSE POR ENSINAR E APRENDER QUÍMICA
}

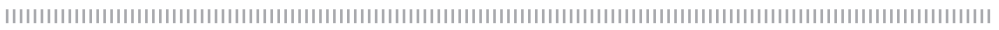

\author{
Judite Scherer Wenzel ${ }^{1}$ \\ Fabiane de Andrade Leite ${ }^{2}$ \\ Jackson Luís Martins Cacciamani ${ }^{3}$ \\ Ronaldo Aurélio Gimenes Garcia ${ }^{4}$ \\ Cláudia Almeida Fioresi ${ }^{5}$ \\ Caroline Zanoto ${ }^{6}$
}

\footnotetext{
1 Doutora em Educação nas Ciências.Professora adjunta da Universidade Federal da Fronteira Sul (UFFS), coordenadora do Subprojeto PIBID Química (Campus Cerro Largo/RS). Contato: juditescherer@uffs.edu.br

2 Doutora em Educação nas Ciências. Professora adjunta da Universidade Federal da Fronteira Sul (UFFS), colaboradora do Subprojeto PIBID Química (Campus Cerro Largo/RS). Contato: fabiane.leite@uffs.edu.br

3 Doutor em Educação em Ciências, Professor adjunto da UFFS, coordenador do subprojeto PIBID Química (Campus Realeza/PR). Contato: jackson.cacciamani@uffs.edu.br

${ }^{4}$ Doutor em Educação. Professor Adjunto da Universidade Federal da Fronteira Sul (UFFS), colaborador do subprojeto PIBID Química (Campus Realeza/ PR). Contato: ronaldo.garcia@uffs.edu.br

${ }^{5}$ Mestre em Educação. Professora Assitente UFFS. Colaboradora do subprojeto PIBID Química (Campus Realeza/PR). Contato: claudia.fioresi@uffs.edu.br

${ }^{6}$ Mestre em Química. Professora substituta Universidade Federal da Fronteira Sul (UFFS) colaboradora do Subprojeto PIBID Química (Campus Realeza/PR). Contato: caroline.ztto@gmail.com
} 


\section{RESUMO}

O presente capítulo tem por intenção publicizar as experiências vividas no Programa Institucional de Bolsa de Iniciação à Docência (PIBID) nos Campi de Cerro Largo/RS e Realeza/PR da Universidade Federal da Fronteira Sul (UFFS). A temática escolhida coletivamente no intuito de dialogarmos é o (des)interesse dos estudantes tanto da escola quanto da universidade frente aos processos de ensinar e de aprender determinados conteúdos estruturantes pertencentes às Ciências, especialmente, Química. Isso tem potencializado algumas ações coletivas nossas "enquanto/como" professores tanto da escola quanto da universidade no sentido de compreendermos as formas, os modos, os tempos e os espaços desse processo educativo diante do momento que estamos vivendo na sociedade contemporânea. Por isso, argumenta em favor da linguagem em todas as suas formas, da interação entre a escola e a universidade, de um processo de formação que é coletivo, da investigação-ação-formação, do educar pela pesquisa e da formação acadêmico-profissional. A docência, num espaço coletivo de formação, tem se mostrado um caminho para a qualificação da formação dos professores (inicial ou continuada) e para o ensino em contexto escolar.

Palavras-chave: Formação de Professores. Educação Química. Interação Escola e Universidade.

\section{INTRODUÇÃO: CONTEXTUALIZAÇÃO}

O foco do presente capítulo consiste em dialogar acerca da necessidade de uma reflexão sobre o (des)interesse do ensinar e aprender Ciências/Química apontando a Iniciação à docência como espaço formativo que promova a (re)significação dos processos educativos pela interação universidade-escola. Tal diálogo decorre das atividades experienciadas no grupo do Programa Institucional de Bolsa de Iniciação à Docência (PIBID) Química da Universidade Federal da Fronteira Sul (UFFS) que já tem um histórico de atividades junto ao Programa, mas de modo especial, o que apresentamos está relacionado às experiências vinculadas 
ao edital Capes, de agosto de 2018. De acordo com o edital, os licenciandos vinculados ao Programa deverão estar matriculados na primeira metade do curso visando a estimular desde o início de sua formação, a observação e a reflexão sobre a prática profissional no cotidiano das escolas públicas de Educação Básica.

Nesse sentido, acenamos à experiência docente como principal aspecto que pode contribuir para motivar o licenciando nessa etapa formativa e, com isso, contribuir para qualificar a formação docente. Assim, compreendemos com Larossa (2002) a experiência como algo que nos toca, que nos acontece, que nos tomba, ou seja, nos diálogos e escritas desenvolvidas foi possível identificarmos o (des)interesse pelo aprender Ciências/Química e a necessária motivação para isso, tanto em contexto escolar como na formação de professores.

Acreditando que um dos caminhos para qualificar o processo de aprender e ensinar seja a qualificação dos espaços formativos dos professores, sejam eles em formação inicial e/ou continuada, apresentamos uma reflexão sobre as nossas crenças e apostas junto ao ensino e a formação de professores, destacando algumas das atividades que estão sendo desenvolvidas e que se relacionam com a promoção da alfabetização científica num movimento de investigação-ação-formação (ALARCÃO, 2010) pela via da pesquisa. O grupo, do qual referimos, está constituído por dois núcleos, um com atividade no município de Cerro Largo/ $\mathrm{RS}^{7}$ que conta com três professores supervisores, professores de

\footnotetext{
7 Ana Lires Oliveira Da Silva, Andriéli Hoffmann dos Santos, Beatriz Soquetta Vedooto, Bianca Oliveira Konzen, Eduarda Kreutz, Eduarda Patan, Gabrielle dos Santos Leite, Izabel Waszkiewics, Jonathan Grützmann Fin, Juliane Oliveira dos Santos, Larissa Fátima Drebes, Larissa Freitas Carloto, Letícia Gabrielhi Rocha, Lisangela Terezinha Cambimba, Lucas Eliezer Perin Diniz, Lucas Morais Brum, Luzilene Rito dos Santos, Maryellen da Rocha Rosa, Morgana Maciel Oliveira, Rafaela Bieger Muenchen, Sabrina Hoffmann, Thalia Brum, Vitor Ferreira Italiano, Daniéli Vitória Goetz Pauli, Eloisa Langer Martiny, Márcia dos Santos da Silva, Giordani Miguel Schnorr (licenciandas e licenciandos) Cristia-
} 
escolas da rede estadual e 27 licenciandos, sendo 24 bolsistas e três voluntários, alunos do curso de Licenciatura em Química da Universidade Federal da Fronteira Sul (UFFS), duas professoras da UFFS, uma atua como colaboradora e outra como coordenadora. E, outro núcleo ${ }^{8}$ com atividades no município de Realeza/ $\mathrm{PR}$, que também conta com três colegas professores supervisores das escolas da Educação Básica e 23 bolsistas do curso de Licenciatura em Química bem como colegas colaboradores no processo formativo para além do professor coordenador.

Nesse espaço formativo, buscamos desenvolver ações e reflexões que possibilitem uma compreensão mais qualificada acerca do ensinar e aprender Química por meio de iniciativas, que contemplam estudos de práticas pedagógicas, compreensões sobre a especificidade da formação docente, estudos do texto da Base Nacional Comum Curricular (BNCC), imersão no contexto escolar com a participação efetiva das licenciandas e dos licenciandos na escola, por meio do acompanhamento de atividades, de planejamentos e com o desenvolvimento de práticas de ensino. Todos esses momentos formativos estão sendo acompanhados

no Rodeski Pires (Escola Estadual de Educação Básica Eugênio Frantz - Cerro Largo/RS), Elisandra Giordani de Menezes (Escola Estadual de Educação Básica Eugênio Frantz - Cerro Largo/RS), Tatiana Roberta Fröhlich Venzke (Escola Estadual Dr. Otto Flach - Cerro Largo/RS).

8 Adrieli Bin, Amanda Regina Fraga de Andrade, Daniel Luiz Paz, Daniela Steinheuser Schiochet, Diego Gabriel de Oliveira, Edilvania Bernardi, Ezequiel Arruda de Alcantara, Fabiana Maria Antunes Rech, Geovane Felipe Padilha, Julia Natalia Gradaschi, Laura Darif Turra, Luan Mohler, Luana Ferrandin Magedanz, Lucas Rodrigues da Silva, Luciano Kellner, Taislaine de Souza Beltrame, Jenifer Maiara da Silva, Alessandro da Silva dos Santos, Jenifer Maiara da Silva, Alessandro da Silva dos Santos, Aline Chaves de Oliveira, Gabriel Barbacovi, Pablo José dos Anjos, Jean Barcelos (licenciandas e licenciandos), Loizete Aparecida Maria Andrade Zabot (Colégio Estadual João Paulo II - Realeza/PR), Rosane Aparecida Bettin Baldissera (Colégio Estadual Guilherme de Almeida - Santa Izabel do Oeste/PR), Márcio Denis Cardoso (Colégio Estadual Doze de Novembro - Realeza/PR). 
por um processo de escrita, de leitura e de diálogo numa perspectiva da pesquisa (DEMO, 1998; MALDANER, 2000; GALIAZZI, 2003; MORAES, RAMOS; GALIAZZI, 2004). Com isso, visamos à publicização e à sistematização das atividades das experiências vivenciadas num movimento que se caracteriza como de investigação-ação-formação.

De modo especial, nossa atenção no presente capítulo está para alguns aspectos que indiciam o (des)interesse pelo ensinar e aprender e indicamos a iniciação à docência pela via da alfabetização científica como um caminho para qualificar esse processo. Para isso apontamos em nossa escrita dois aspectos: 1) a iniciação à docência como modo de qualificar a formação inicial e, 2) a iniciação à docência como modo de qualificar o ensino de Química em contexto escolar. Assim, na sequência passamos a discorrer os aspectos que conduziram nosso olhar às ações do PIBID Química realizadas no Campus Cerro Largo/RS e no Campus Realeza/PR.

\section{A INICIAÇÃO À DOCÊNCIA COMO MODO DE QUALIFICAR A FORMAÇÃO INICIAL DE PROFESSORES}

"[...] quando adentrei em sala de aula, fiquei muito feliz, pelo fato de não ser mais uma aluna do Ensino Médio, mas como uma futura professora de química [...] quero que fique gravado em minha memória como um dia que simboliza o início de um ciclo cheio de aprendizado e crescimento." (Excerto do diário de bordo de uma licencianda no seu primeiro contato com a escola).

A escolha por iniciar esta parte da escrita trazendo um o excerto da escrita de um diário de bordo de uma bolsista está relacionada às contribuições do Programa Institucional de Bolsa de Iniciação à Docência (PIBID) ao início do processo de constituição docente. Estar em sala de aula em outra posição, de acordo 
com a bolsista, possibilitou-lhe compreender o papel de um professor e, com isso, reconhecer a importância da sua formação de tal maneira que expressa o desejo de guardar na memória o registro desse momento. As possibilidades de qualificar a formação do futuro professor de Química por meio do PIBID são inúmeras e têm sido apresentadas em pesquisas realizadas ao longo dos últimos anos (DINIZ-PEREIRA, 2008; AMARAL, 2012).

Com essas perspectivas, compreendemos que a inserção do licenciando no espaço educacional, o estudo acerca da constituição docente, a elaboração e os estudos de práticas pedagógicas alicerçadas com o Educar pela Pesquisa se constituem como caminhos para qualificar a formação de professores e a Educação Química, ou seja, é um "ciclo cheio de aprendizado e crescimento". Ainda, a inserção do licenciando no contexto escolar está em coerência do que é apontado por Guimarães $(2014$, p. 5) na apresentação do livro Um estudo avaliativo do Programa Institucional de Bolsa de Iniciação à Docência (PIBID), "[...] os alunos de licenciatura exercem atividades pedagógicas em escolas públicas de Educação Básica, contribuindo para a integração entre teoria e prática, para a aproximação entre universidades e escolas e para a melhoria de qualidade da educação brasileira".

O mesmo autor $(2014$, p. 5) aponta que "[...] a ação dos licenciandos e de seus orientadores têm o potencial de elevar a qualidade do trabalho nas escolas públicas e nas instituições formadoras". A potencialidade do PIBID no processo de formação de professores que integra licenciandos, professores da escola da Educação Básica e professores da universidade é apontado por Diniz-Pereira (2008) como formação acadêmico-profissional que proporciona a ampliação e a qualificação dos laços da universidade com a escola e a comunidade.

E, oportuniza a (re)construção e (re)significação das teorias e paradigmas acerca das competências concernentes ao processo educativo. Isso vem ao encontro da perspectiva histórico 
cultural (VIGOTSKI, 2009) de constituição do sujeito. No caso do professor, por exemplo, os processos de ensinar e de aprender, as metodologias, a inclusão, a avaliação, o currículo, as políticas públicas de investimento na Educação, a gestão escolar, os conteúdos (conceituais, atitudinais, procedimentais, éticos, morais, religiosos, políticos, econômicos, culturais, sociais etc.), dentre outros tantos aspectos que são essenciais e que são necessários de serem contemplados na iniciação à docência.

Num direcionamento que proporciona compreender o contexto escolar como o lócus da atuação profissional (NÓVOA, 2009) e como modo de iniciação à docência caracterizando-se num espaço-tempo de produção de conhecimentos e saberes. É nisso que consiste o registo das práticas, a reflexão sobre o trabalho e o exercício da avaliação, estes podem ser considerados, segundo Nóvoa (2009), elementos centrais para o aperfeiçoamento e a inovação.

Daí ressaltamos a importância das múltiplas interações do compartilhamento de experiências a serem vivenciadas, das escritas, diálogos e leituras que são constantemente realizadas seja por meio do diário de bordo, portfólios ou webfólios etc. Alarcão (2010, p. 49) aponta que, em tal movimento formativo, encontramos um triplo diálogo: “[...] um diálogo consigo próprio, um diálogo com os outros incluindo os que antes de nós construíram conhecimentos que são referência e o diálogo com a própria situação.", tal movimento contribui para a autonomia dos participantes.

Acreditamos que é na multiplicidade, na partilha entre pares, nas vivências e experiências em contexto escolar e no estudo do referencial teórico integrando-o com a prática que é possível um avanço nas concepções do que é ser professor e do que é ensinar e aprender, construindo dessa forma a identidade docente. Os espaços formativos que são possíveis de serem vivenciados no PIBID promovem o diálogo compartilhado da prática e permitem aos professores, em diferentes estágios de formação, um 
processo de reflexão na e sobre a ação ressignificando a sua prática e a compreensão acerca do ser professor. Assim, apostamos num acompanhamento constante pela escrita, leitura e diálogos pela via do Educar pela Pesquisa e da investigação-ação-formação em contextos práticos, em práticas baseadas na realidade no contexto da sala de aula que, pela vivência mediada teoricamente se tornam experiências (LAROSSA, 2002).

Em seus estudos sobre a formação de professores no Brasil, Gatti e Barreto (2009) apontam que um dos graves problemas dos cursos de licenciaturas é a distância que existe entre os conteúdos trabalhados na universidade e a realidade da escola de Educação Básica. Assim quando o licenciando conclui o curso e vai trabalhar na escola pública, há um "choque de realidade" e esse se sente despreparado para enfrentar o cotidiano escolar. Nesse aspecto, $o$ PIBID é uma política pública que de fato insere o licenciando(a) nas instituições de ensino, estimulando o estudante a refletir, desde o início, sobre os desafios da escola e formas criadoras e criativas de superá-los. Nessa mesma direção estão as Diretrizes Nacionais Curriculares para Formação Inicial em Nível Superior e Formação Continuada de Professores n. 2, de 2015, no inciso VII do Artigo $8^{\circ}$ afirma que os egressos devem ter condições para:

Identificar questões e problemas socioculturais e educacionais, com postura investigativa, integrativa e propositiva em face de realidades complexas, a fim de contribuir para a superação de exclusões sociais, étnico-raciais, econômicas, culturais, religiosas, políticas, de gênero, sexuais e outras [...] (BRASIL, 2015).

Além disso, salientamos a importância de aproximar cada vez mais os licenciandos e professores no chão da escola. Como Nóvoa (2009, p. 16) pontua, "É preciso passar a formação de professores para dentro da profissão [...] quero sublinhar a necessidade de os professores terem um lugar predominante na forma- 
ção dos seus colegas". E para que isso seja possível, a comunidade dos formadores de professores e a comunidade dos professores precisam se tornar mais permeáveis e imbricadas.

O que queremos dizer é que essa cultura profissional, apontada por Nóvoa (2009, p. 30), consiste que "Ser professor é compreender os sentidos da instituição escolar, integrar-se numa profissão, aprender com os colegas mais experientes. É na escola e no diálogo com os outros professores que se aprende a profissão".

Dessa forma, acreditamos que com o PIBID essa aproximação é facilitada e pode atuar como um grande alicerce para mudanças significativas, que não atuem em situações pontuais apenas, mas que configure um processo efetivo de formação na ação docente e no trabalho escolar. Tais prerrogativas são identificadas nos questionários ${ }^{9}$ respondidos pelos licenciandos. Ao descreverem sobre a sua participação no PIBID, entre outros, apontaram que:

"No PIBID temos a oportunidade de entrar em sala de aula"; "vou me acostumando a falar em público"; "estou aprendendo a ser professor(a)"; "o que me motiva a participar do PIBID é a formação reflexiva [...] as palestras, as leituras, os encontros de formação"; "gosto do coletivo, de ter um grupo de amigos"; "escrever sobre a prática." (Recortes da escrita dos licenciandos nos questionários de acompanhamento do Programa).

Destacamos de modo especial o reconhecimento da especificidade da docência, o licenciando ao mencionar "estou aprendendo a ser professor" retrata entre outros, as particularidades do profissional, da constituição docente, ou seja, ninguém nasce sendo professor, mas é necessário aprender a ser. Nessa direção, vale ressaltar os estudos de Shulman (1986) que apontam co-

\footnotetext{
9 Os questionários consistem num movimento sistemático de acompanhamento do Programa.
} 
nhecimentos e saberes do profissional professor para além do conteúdo específico, mas que requerem tanto um conhecimento pedagógico geral e do conteúdo um conhecimento mais amplo sobre o processo de ensinar e aprender e sobre o contexto escolar. Nesse movimento de formação os nossos licenciandos aprendem coletivamente com os nossos colegas professores das escolas da Educação Básica e conosco a serem professores, isto é, um processo de formação de professores que ocorre no seu espaço profissional. Daí a necessidade de oportunizar de forma qualificada o aprender a ser professor. E, um modo para isso, é otimizar no decorrer da formação inicial a articulação entre a escola da Educação Básica e a Universidade num movimento que oportunize ao licenciando "entrar em sala de aula", num processo de "formação reflexiva" que promova o "escrever sobre a prática".

Buscamos no PIBID qualificar a compreensão acerca das especificidades da docência por meio do reconhecimento do contexto real de ensino e pela via da escrita e da leitura reflexiva. Nóvoa (1995) ao considerar a formação de professores aponta que o conhecimento essencial de um professor é construído na escola, por meio da experiência e da reflexão sobre a experiência, e aponta que:

[...] a formação passa por processos de investigação, diretamente articulados com as práticas educativas. Neste sentido, a dinamização de dispositivos de investigação-ação e de investigação-formação pode dar corpo à apropriação pelos professores dos saberes que são chamados a mobilizar no exercício da sua profissão. (NÓVOA, 1995, p. 28).

Com isso, reforçamos a importância do Programa de iniciação à docência como espaço formativo que possibilita a inserção dos professores em formação inicial em contexto escolar. E, de modo especial, destacamos as escritas reflexivas como possibili- 
dade de investigação na e sobre a prática. Com isso, aliado à prática de escrita, realizamos encontros de "leituras", de "palestras" visando a qualificar a relação teoria e prática e a compreensão acerca do ser professor, especialmente, no que tange ao ensinar e ao aprender Química. Segue um diálogo acerca das contribuições do PIBID frente ao processo de ensinar Química em contexto escolar.

\section{A INICIAÇÃO À DOCÊNCIA COMO MODO DE QUALIFICAR O ENSINO DE QUÍMICA EM CONTEXTO ESCOLAR}

Ao considerarmos o ensino de Química, apontamos a necessidade de superar a visão simplista de Química, ou ainda, de despertar o interesse dos estudantes do Ensino Médio para essa área do conhecimento e, possibilitar a significação dos conteúdos diversos que, especialmente, contribuam na potencialidade da humanização. Para isso é necessário que as licenciandas e os licenciandos, na condição de professores em formação inicial, consigam fazer uma leitura atenta, densa e intensa do mundo sob os olhares dos processos físicos, químicos, biológicos, bioquímicos, sociais, históricos, culturais, políticos, econômicos etc. E, nesse ínterim, a linguagem em toda a sua complexidade é um aspecto importante no sentido de construir e reconstruir as teorias e os paradigmas acerca da nossa constituição enquanto/como professores, ou seja, a linguagem nos constitui como seres humanos Homo sapiens sapiens.

Por isso, no momento que escrevemos, lemos e dialogamos acerca das nossas incertezas, inquietudes, alegrias e encantamentos a respeito da nossa constituição enquanto/como professores estamos produzindo currículo, além de estarmos construindo a nossa identidade docente. Afinal de contas no que acreditamos? De que maneira conseguimos estreitar o distanciamento entre a teoria e a prática? Quais teorias sustentam a nossa prática 
pedagógica? Que epistemologias produzimos no espaço-tempo da sala de aula de Ciências nos Anos Finais do Ensino Fundamental e em Química no Ensino Médio? Que conteúdos escolhemos no momento que organizamos o planejamento da nossa sala de aula tanto na escola quanto na universidade? O quanto escrevemos e lemos por amorosidade? O quanto potencializamos na nossa sala de aula os processos de escrever, de ler e de dialogar? De que maneira compreendemos o papel social, histórico, cultural, político e intelectual da nossa profissão na sociedade contemporânea? Enfim, poderíamos elencar muitas outras perguntas que sustentam argumentos importantes no sentido de compreendermos com mais complexidade a nossa constituição enquanto/como professores [...] contudo, no intuito de elencarmos algumas "respostas" a esses e outros tantos questionamentos precisamos entender a importância de nos constituirmos professores pesquisadores. Isto é, pesquisarmos aquilo que fazemos na nossa sala de aula nessa interação entre a escola, a universidade e a comunidade.

Os estudos e os estímulos à inovação, à criatividade, à inventividade, à inclusão, à ética profissional e à interação dos pares são vistos como precursores das ações propostas. Daí a importância dos planejamentos coletivos que são desenvolvidos nos grupos de pesquisa, dos processos de escrita e de leitura, dos momentos de pesquisa acerca da própria prática pedagógica, das incertezas, das inquietudes, das alegrias e dos encantamentos com o processo formativo. $\mathrm{O}$ coletivo, também é destaque nas escritas dos licenciandos:

"[...] estou adorando voltar para a escola, o pessoal que compartilha o turno comigo, e com a professora superviso$\mathrm{ra}$, são muito legais trocamos ideias e realizamos os planejamentos juntos." (Diário de bordo de uma bolsista).

Ainda, ressaltamos a importância da inserção do PIBID Química no contexto da Educação Básica enquanto espaço de 
construção de estratégias de ensino que buscam qualificar o processo de aprender em sala de aula, conforme apresentado no excerto do diário citado. Os licenciandos, em colaboração com os professores supervisores, realizam planejamentos de atividades inovadoras a serem realizadas em sala de aula, tendo como foco o desenvolvimento da alfabetização científica. Assim, contribuem de forma direta com o aprender dos conceitos químicos e, também, com o interesse dos estudantes.

Nessa direção, podemos trazer o que Morin (2001) fala sobre Educação, salientando que "[...] deve contribuir para a autoformação da pessoa (ensinar a assumir a condição humana, ensinar a viver) e ensinar como se tornar cidadão." (MORIN, 2001, p. 65). É nessa via de mão dupla que a alfabetização cientifica pode atuar como eixo norteador na prática docente. A alfabetização científica vai muito além de um mero repertório de conteúdos que devem ser aprendidos pelos alunos, mais do que isso é uma nova forma de relacionar-se com o mundo e com os fatos da vida cotidiana de uma forma sempre questionadora, problematizadora e inquieta que desperta novas descobertas e também novas perguntas diante do mundo e dos fenômenos naturais. Os fatos da natureza não apartados da vida social, política, econômica, cultural e outras, mas estão intimamente relacionados. Apresentar essa relação complexa e dinâmica dos conhecimentos é sem dúvida é um grande desafio para professores, licenciandos e alunos da Educação Básica, por isso a importância do trabalho coletivo que é vivenciado no PIBID.

Nessa perspectiva, identificamos que o trabalho colaborativo realizado com os professores supervisores também contribui, de forma indireta, para a qualificação do ensino de Química no contexto escolar. Compreendemos que a relação de diálogo estabelecida, nos diferentes momentos formativos, entre formadores, licenciandos e professores de escola auxiliam na (re)significação da compreensão do que é o ensinar e aprender e do ser 
professor. Segue um excerto pincelado da escrita do Diário de Bordo de uma das professoras supervisoras:

\begin{abstract}
"[...] foi uma manhã muito interessante na qual aprendi muito sobre como o aluno aprende. Sendo assim, preciso rever a maneira como ensino, como organizo os conteúdos de como posso aprimorar e melhorar as minhas aulas, com o objetivo que os alunos aprendam mais e melhor." (Diário de Bordo, de uma professora supervisora).
\end{abstract}

Assim, no que se refere aos professores de escola, temos observado a tomada de consciência sobre a sua prática pelo movimento de reflexão. Isso também reflete no uso de diferentes metodologias em sala de aula, fruto do envolvimento desses profissionais com o PIBID e com as múltiplas interações estabelecidas pela via da formação-investigação-ação que propomos em nossas atividades. De modo especial, destacamos que a nossa perspectiva formativa contempla a sala de aula ancorada na pesquisa, a qual, proporciona que as diversas formas de linguagem (escrita, leitura, argumentação, cinema, música, teatro, literatura, fotografia, divulgação da ciência, arte etc.) sejam exploradas num caminho a percorrer outras formas de ensinar, de aprender e de avaliar numa perspectiva mais processual, dialógica e aprendente. Os estudos e os estímulos à inovação, à criatividade, à inventividade, à inclusão, à ética profissional e à interação dos pares são vistos como precursores das ações propostas.

Daí novamente ressaltamos a importância dos planejamentos coletivos que são desenvolvidos, dos processos de escrita e de leitura, dos momentos de pesquisa acerca da própria prática pedagógica, das incertezas, das inquietudes, das alegrias e dos encantamentos com o processo formativo. Esse, por sua vez, não é algo único e homogêneo. Ninguém aprende de uma mesma forma, com os mesmos processos e metodologias. Há que se ter em conta a necessidade de uma diversidade de recursos, abordagens 
e linguagens que possam de fato contribuir com uma formação mais ampla que envolva não apenas os conhecimentos técnicos e específicos, mas principalmente que saiba lidar com pessoas e suas demandas de forma sensível, acolhedora, humanizadora e ética. Como afirma Freire (1996), na condição de professores, é muito fácil não fazer quando somente nós sabemos o que de fato temos que fazer.

Portanto, enfatizamos que o PIBID se configura como um espaço de suma relevância na formação inicial dos licenciandos, possibilitando aos futuros professores a oportunidade de levantarem e refletirem sobre alguns problemas, carências e necessidades reais de ensino-aprendizagem nas escolas participantes. Para tanto, ancorados na pesquisa e na multiplicidade dos fundamentados teóricos da área de ensino de Ciências que eles possam pensar e desenvolver atividades em sala de aula capazes de mobilizar mudanças significativas para os processos de aprendizagem na escola.

\section{CONSIDERAÇÕES FINAIS}

As reflexões realizadas no presente capítulo decorrem das vivências formativas que tivemos, enquanto professores coordenadores e colaboradores do PIBID, dos cursos de Licenciatura em Química dos Campi da UFFS de Cerro Largo/RS e de Realeza/ PR. Para a escrita conduzimos nosso olhar às ações realizadas ao longo de dois semestres de inserção de licenciandos bolsistas e voluntários nas escolas, ainda o movimento formativo realizado com supervisores, professores das escolas envolvidos diretamente no Programa.

Nesse sentido, ressaltamos a importância do Programa na qualificação da formação inicial de futuros professores de Química. Ainda, as possibilidades do trabalho realizado no processo de qualificar o ensino de Química na Educação Básica. E, como 
proposição para qualificar o interesse pelo ensinar e aprender química, ressaltamos a necessidade de dialogarmos coletivamente alguns aspectos, como:

- a interação entre a escola da Educação Básica, a Universidade e a Comunidade é essencialmente formativa e transformadora;

- as diversas formas de linguagem (escrita, leitura, argumentação, cinema, literatura, música, arte, teatro, etc.) potencializam novos espaços e tempos de ensinar e de aprender;

- o processo de alfabetização científica contribui na compreensão da realidade de modo mais intenso, denso e crítico;

- o (des)interesse dos estudantes nos processos educativos tem relação com aspectos que dizem respeito ao processo de formação de professores, a organização do currículo tanto na escola quanto na universidade, ao entendimento acerca dos conteúdos (pois historicamente no nosso processo de formação enquanto professores somente os conteúdos específicos, na maioria dos casos, adquirem significado), dentre outros aspectos;

- o processo de formação de professores precisa problematizar os processos de ensinar e de aprender, pois isso tem um sentido importante nos processos educativos tanto na escola quanto na universidade.

E, com isso, reiteramos a importância do fortalecimento e da publicização das atividades experienciadas nos diferentes Programas de iniciação à docência, uma vez que tais programas têm permitido o estabelecimento de um diálogo, ainda que ceivado por conflitos, entre os diferentes sujeitos da escola e da universidade propiciando um ambiente de aprendizagem, reflexão, debates com recuos e avanços como qualquer outra atividade humana. Essa é uma experiência ímpar na história da formação de professores no Brasil que de fato tem contribuído para uma nova 
perspectiva de educação em os agentes do processo devem atuar ativamente no domínio dos conhecimentos e das práticas que constituem, ainda que inicialmente, os saberes do ser professor.

\section{REFERÊNCIAS}

ALARCÃO, Isabel. Professores reflexivos em uma escola reflexiva. 8.ed. São Paulo: Cortez, 2011.

AMARAL, Edenia Maria Ribeiro. Avaliando contribuições para a formação docente: uma análise de atividades realizadas no PIBID Química da UFRPE. Química Nova na Escola, São Paulo, v. 34, n. 4, p. 229-239, 2012.

BRASIL. Resolução CNE/CP n. 02/2015, de 1º de julho de 2015. Conselho Nacional de Educação. Define as Diretrizes Curriculares Nacionais para a formação inicial em nível superior (cursos de licenciatura, cursos de formação pedagógica para graduados e cursos de segunda licenciatura) e para a formação continuada. Diário Oficial [da] República Federativa do Brasil, Brasília, DF, 2 jul. 2015. Seção 1, n. 124 , p. 8-12.

DEMO, Pedro. Educar pela Pesquisa. Campinas: Autores Associados, 1998.

DINIZ-PEREIRA, Júlio Emílio. A formação acadêmico-profissional: Compartilhando responsabilidades entre as universidades e escolas. Trajetórias e processos de ensinar e aprender: didática e formação de professores. In: ENDIPE - PONTIFÍCIA UNIVERSIDADE CATÓLICA DO RIO GRANDE DO SUL (PUCRS), XIV., 2008, Porto Alegre. Anais [...] Porto Alegre: [s.n.], 2008.

FREIRE, P. Pedagogia da autonomia: saberes necessários à prática educativa. São Paulo: Paz e Terra, 2006.

GALIAZZI, Maria do Carmo. Educar pela Pesquisa: ambiente de formação de professores de Ciências. Ijuí: Unijuí, 2003. 
GATTI, Bernadete Angelina; BARRETTO, Elba Siqueira de Sá.

Professores do Brasil: impasses e desafios. Brasília, DF: UNESCO, 2009.

GUIMARÃES, Jorge Almeida. Apresentação. In: FUNDAÇÃO

CARLOS CHAGAS. Um estudo avaliativo do Programa

Institucional de Bolsa de Iniciação à Docência (PIBID).

Pesquisadores Bernardete A. Gatti, Marli E. D. A., André, Nelson A. S. Gimenes e Laurizete Ferragu. São Paulo: FCC, 2014.

LARROSA, Jorge. Notas sobre a experiência e o saber de experiência. Tradução de João Wanderley Geraldi. Revista Brasileira de Educação, Rio de Janeiro, n. 19, p. 20-28; 168-169, jan./fev./mar./abr. 2002.

MALDANER, Otávio Aloísio. A formação inicial e continuada de professores de Química: professores/pesquisadores. Ijuí: Unijuí, 2000.

MORAES, Roque; RAMOS, Maurivan Güntzel; GALIAZZI, Maria do Carmo. A epistemologia do aprender no educar pela pesquisa em Ciências: alguns pressupostos teóricos. In: MORAES, Roque; MANCUSO, Ronaldo (org.). Educação em Ciências: produção de currículos e formação de professores. Ijuí: Unijuí, 2004.

MORIN, E. Os sete saberes necessários à educação do futuro. São Paulo: Cortez, 2001.

NÓVOA, António. Formação de professores e profissão docente. In: NÓVOA, António (coord.). Os professores e a sua formação. 2. ed. Lisboa: Publicações D. Quixote, 1995. p. 13-33.

NÓVOA, António. Professores - Imagens do futuro presente. Lisboa: Educa, 2009.

SHULMAN, Lee S. Those Who Understand: knowledger owth in teaching. Educational Researcher, [s.l.], v. 15, n. 2, p. 4-14, fev. 1986. Disponível em: http://www.fisica.uniud.it/URDF/masterDidSciUD/ materiali/pdf/Shulman_1986.pdf. Acesso em: 12 maio 2015.

VIGOTSKY, Lev Semenovich. A construção do pensamento e da linguagem. Tradução de Paulo Bezerra. 2. ed. São Paulo: WMF Martins Fontes, 2009. 